\title{
The Effects of Fiscal Policy in a Small Open Economy with a Fixed Exchange Rate
}

Ravn, Søren Hove; Spange, Morten

Published in:

Open Economies Review

Publication date:

2014

Document version

Early version, also known as pre-print

Citation for published version (APA):

Ravn, S. H., \& Spange, M. (2014). The Effects of Fiscal Policy in a Small Open Economy with a Fixed Exchange

Rate. Open Economies Review, 25(3), 451-476. http://link.springer.com/article/10.1007/s11079-013-9288-2 


\title{
The Effects of Fiscal Policy in a Small Open Economy with a Fixed Exchange Rate
}

\author{
Søren Hove Ravn • Morten Spange
}

Published online: 15 October 2013

(C) Springer Science+Business Media New York 2013

\begin{abstract}
We study the empirical effects of fiscal policy in Denmark since the adoption of a fixed exchange rate policy in 1982. Denmark's fixed exchange rate implies that the nominal interest rate remains fixed after a fiscal expansion, facilitating a substantial impact of the fiscal stimulus on the real economy. On the other hand, the large degree of openness of the Danish economy means that a sizeable share of the fiscal stimulus will be directed towards imported goods. Our results suggest that the 'monetary accomodation channel' dominates the 'leakage effect' in the short run. We demonstrate that fiscal stimulus has a rather large impact on economic activity in the very short run, with a government spending multiplier of 1.1 on impact in our preferred specification. We also find that the effects of fiscal stimulus are rather shortlived in Denmark, with the effect on output becoming insignificant after around two years. The fiscal multiplier is above 1 only in the first quarter, and drops to 0.6 one year after the shock. We also find that in the short run, the government spending multiplier is larger than the tax multiplier. Finally, we demonstrate that exogenous shocks to government spending account for less than $10 \%$ of the movements in output over the business cycle in Denmark.
\end{abstract}

The views expressed in this paper are those of the authors, and do not necessarily correspond to those of Danmarks Nationalbank. The authors would like to thank Michael Bergman, Ester Faia, Francesco Furlanetto, Jesper Lindé, Ivan Petrella, two anonymous referees, and colleagues at Danmarks Nationalbank for useful comments and suggestions. Any remaining errors are our own.

S. H. Ravn $(\bowtie) \cdot$ M. Spange

Danmarks Nationalbank, Copenhagen, Denmark

e-mail:shr@nationalbanken.dk

M. Spange

e-mail: msp@nationalbanken.dk

S. H. Ravn

University of Copenhagen, Copenhagen, Denmark 
Keywords Fiscal policy $\cdot$ Fixed exchange rates $\cdot$ Structural VARs

JEL Classification E32 $\cdot$ E62 $\cdot$ F41

\section{Introduction}

The macroeconomic effects of discretionary fiscal policy have been the subject of a longstanding, academic debate. ${ }^{1}$ Since the outbreak of the financial crisis the effectiveness of fiscal policy as a tool for stabilising the economy in response to a negative shock has also received strong attention from governments and policy institutions. As demand from the private sector fell sharply around 2008, most countries increased government spending in an attemt to stimulate the economy. However, as the need for fiscal consolidation became evident, the stimulus was to a large extent withdrawn. The widespread use of fiscal policy in response to the crisis has sparked a debate about the size of fiscal multipliers and the appropriate use of fiscal policy. In particular, research by the IMF has found that there has been a tendency throughout the crisis to underestimate the size of the fiscal multipliers (see Blanchard and Leigh 2013). This is critical since the optimal pace with which fiscal stimulus is withdrawn hinges on the size of the multipliers.

The present paper adds to this debate by presenting an empirical analysis of the effects of fiscal policy in Denmark. A case study of Danish fiscal policy is interesting for a number of reasons. Whereas most empirical studies of fiscal policy tend to focus on large countries, Denmark is a small open economy with a fixed exchange rate and a large public sector. While the large degree of openess to trade would tend to reduce the effectiveness of ficsal policy in terms of stabilizing the domestic economy, the fixed exchange rate and the size of the public sector should contribute to a large multiplier. Moreover, Danish fiscal policy has been the subject of some attention since the publication of Giavazzi and Pagano (1990) where the Danish situation in the 1980s was used as an example of an "expansionary fiscal contraction". The expansionary fiscal contractions hypothesis is largely supported by Bergman and Hutchison (2010), whereas for example Andersen (1994) has challenged the result.

Fiscal policy has a direct as well as an indirect effect on output. The direct effect reflects that higher government consumption and investment add directly to aggregate demand. The indirect effect works via the response of private consumption and investment as well as net trade and depends on the characteristics of the economy. Two important characteristics are the exchange rate regime and the degree of openness to international trade. A range of economic models predict that fiscal policy has a larger effect on output under fixed exchange rates than in a floating exchange rate regime. For example, in a baseline New Keynesian model of an open economy with a floating exchange rate, the central bank is likely to react to a fiscal expansion by raising the interest rate to keep inflation at bay. Instead, with a fixed exchange rate, the central bank does not raise the interest rate in response to an increase in

\footnotetext{
${ }^{1}$ We refer the reader to Coenen et al. (2012) or Hebous (2011) for extensive surveys on this literature.
} 
domestic inflation. This more accomodative stance of monetary policy facilitates a larger increase in output. Likewise, in the standard Mundell-Fleming model of an open economy, a fiscal expansion (a rightward shift of the IS curve) increases output and the interest rate and leads to a deterioration of the current account. The increase in the interest rate tends to counter the effect on aggregate demand, and further leads to capital inflows and an appreciation of the currency. A country with a fixed exchange rate therefore has to expand the money supply to offset the increase in the interest rate, leading to a larger response of output under a fixed exchange rate.

On the other hand, part of the increase in domestic demand following a fiscal expansion will be directed towards goods produced abroad. This 'leakage' effect is likely to dampen the size of the fiscal multiplier (Beetsma and Giuliodori 2011). So while Denmark's exchange rate regime would tend to result in a large fiscal multplier, the large degree of openness of the Danish economy, with imports amounting to around $50 \%$ of GDP in recent years, would work in the other direction.

While the interest rate effect associated with the exchange rate regime has traditionally received more attention in the literature, the relative importance of these two opposite effects is ultimately an empirical question which we seek to address in this paper. To this end, we employ a structural vector autoregressive (SVAR) model, and follow the identification strategy first described by Blanchard and Perotti (2002). As we are considering a country for which economic fluctuations abroad are very important, we augment the SVAR approach of Blanchard and Perotti to take into account business cycle movements in Denmark's most important trading partners; Germany and Sweden.

Our empirical results indicate that the fiscal multiplier in Denmark is relatively large in the short run. For the period 1983-2011, i.e. where the Danish exchange rate has been pegged towards first the German Mark and subsequently to the Euro, we find an estimated government spending multiplier of 1.1 on impact. However, we also find that the expansionary effects of government spending die out quickly. The multiplier is above 1 only in the first quarter in our baseline specification, and the effect on output becomes insignificant after around two years. As the stimulus is withdrawn, the effect on economic activity dies out. This suggests that while changes in government spending are an effective tool for short term stabilisation policies, the dynamic effects of government spending in Denmark are small.

The relatively large spending multiplier suggests that in the short run, the interest rate effect is indeed more important than the leakage effect. On the contrary, the fact that the effect on output is rather short-lived suggests that after a while, the opposite seems to be the case. There are, however, other potential explanations for the short-lived effects of fiscal stimulus in Denmark. As prices and wages start to adjust, the relative price of Danish goods and services will rise, inducing Danish as well as foreign consumers to substitute away from these. Given the large export share in the Danish economy, the resulting drop in exports is likely to offset the rise in domestic government spending. Moreover, Denmark has large automatic fiscal stabilizers (Girouard and André 2005). These tend to dampen the persistence of economic shocks, including shocks to government spending.

Our results are consistent with other recent, empirical findings. Ilzetzki et al. (2013) study a sample of 44 countries, and find a government spending multiplier 
of around 1.4 in economies operating under fixed exchange rates, while the multiplier is much lower (and significantly so) in countries with floating exchange rate regimes. Corsetti et al. (2012) study the effects of fiscal policy in 17 OECD countries, and also find a significantly higher fiscal multiplier under fixed exchange rates. Beetsma and Giuliodori (2011) find a fiscal multiplier around 1.2 for a sample of 14 member countries of the European Union. Bergman and Hutchison (2010) study the effects of fiscal policy in Denmark in a setup related to ours, but with a sample from 1971-2000, and with specific focus on the effects of the Danish fiscal contraction in the mid-1980's. Our results are in general consistent with their findings, although some differences arise due to the use of different model specifications and different sample periods. Finally, it is worth emphasising that the fiscal multiplier found in this paper is substantially larger than the 0.5 that forecasters tended to assume for advanced economies during the recent financial crisis, cf. Blanchard and Leigh (2013).

We also compute the tax multiplier which measures the impact on output of an exoganous change in tax revenues. This is found to be substantially smaller than the spending multiplier, consistent with the intuition that private savings are likely to rise following a tax cut whereas government spending adds one-to-one to aggregate demand. In the short term changes to spending are therefore more effective than tax changes in stabilising the economy. This is particularly likely to be the case when there is a considerable degree of spare capacity in the economy and firms and households are reluctant to spend. However, we argue that the methodology applied here does not sufficiently capture the structural benefits from lower taxes that may arise in the medium to long term.

One of the key insights of the recent literature on fiscal policy is that the government spending multiplier is not constant, but varies substantially over time and across countries (Favero et al. 2011; Auerbach and Gorodnichenko 2012; Blanchard and Leigh 2013). Motivated by this finding, we study how the fiscal multiplier in Denmark has evolved over time since the early 1980's. While Denmark adopted a fixed exchange rate in 1982, credibility over the currency peg was not gained overnight. Therefore, the effectiveness of fiscal policy is likely to have increased over time as Denmark has gained credibility around its fixed exchange rate. ${ }^{2}$ On the other hand, the share of imports to GDP has approximately doubled over the same period, pointing towards a substantial increase in the leakage effect, which would tend to reduce the multiplier. We find that the government spending multiplier in Denmark has in fact remained relatively stable over time. The multiplier is close to one in each of the decades included in our sample. This suggests that the impact of increased credibility around the currency peg and the effect of the increase in the import share have roughly offset each other over this period.

While the observed effect of fiscal policy on output is as expected, our results differ from those usually found in the literature in one important aspect. We find that

\footnotetext{
${ }^{2}$ In addition, international capital mobility has increased during our sample due to financial liberalization. In accordance with the description of the effects of fiscal policy under a fixed exchange rate in the MundellFleming model above, this also suggests an increase in the fiscal multiplier over time.
} 
private consumption drops on impact in response to an increase in government spending. ${ }^{3}$ This is different from most studies following the approach of Blanchard and Perotti (2002), which tend to find an increase in private consumption. On the other hand, studies in the tradition of Ramey and Shapiro (1998) tend to find a drop in private consumption, more in line with our results. ${ }^{4}$ However, we find the response of consumption to be significantly different from zero only on impact, after which the response is very close to zero. We argue that the 'Ricardian' response of private consumption in Denmark may be explained by the fact that Danish households have better access to smoothing their consumption via the use financial markets than households in other countries. This implies a weakening of the effect on consumption of changes to private income brought about by changes in government spending. In addition, Danish fiscal policy is very transparent. Since the 1990's fiscal policy has been guided by a focus on medium term budget balance. The focus on budget balance in the medium term implies that consumers anticipate that an unexpected increase in fiscal spending will eventually have to be met by lower public (or private) spending in the future.

Our finding of a 'Ricardian' response of private consumption is per se in line with the conclusion of Giavazzi and Pagano (1990), who study the Danish fiscal consolidation in 1982-83 which marked the end to a prolonged period of unsound public finances. They find that the contraction resulted in a pickup in private consumption. As fiscal policy was tightened and public finances improved, firms and households revised up their expectations about future private sector income, giving rise to a sharp increase in demand. However, this much acclaimed example of an expansionary fiscal contraction is a special case which cannot be generalised to periods with less severe policy reactions. In fact, our finding that the government spending multiplier has remained close to one throughout our sample, including in the 1980's, goes against the expansionary fiscal contraction hypothesis.

To shed additional light on the importance of fiscal policy in Denmark, we present historical decompositions of output fluctuations. We document that movements in government spending account for a small fraction of output fluctuations. Our decomposition also suggests that Danish policymakers have not always been successful in conducting a countercyclical fiscal policy that might alleviate the fluctuations coming from abroad.

The rest of this paper is structured as follows: In Section 2, we introduce our SVAR model, and discuss the data, our choice of variables etc. We present our results about the effects of government spending as well as various extensions and robustness checks in Section 3, while Section 4 describes the effects of tax changes. In Section 5, we use the estimated SVAR-model to undertake historical variance decompositions. Finally, Section 6 concludes.

\footnotetext{
${ }^{3}$ The reason why the fiscal multiplier can be larger than 1 even though private consumption drops is that we find a rise in private investment on impact, after which it becomes insignificant

4 This literature focuses on anticipation effects by assuming that agents react to fiscal policy shocks when they are announced, rather than when they are implemented.
} 


\section{Empirical Model}

Our baseline empirical model is a VAR model with 4 endogenous variables: Foreign trade-weighted GDP $\left(F_{t}\right)$, domestic government spending $\left(G_{t}\right)$, domestic private consumption $\left(C_{t}\right)$, and domestic output $\left(Y_{t}\right)$. For $F_{t}$, we use a weighted average of GDP in Germany and Sweden, Denmark's two most important trading partners, weighted by each country's share (in 1995) in the computation of the real effective rate of the Danish Krone by Danmarks Nationalbank (Pedersen and Plagborg-Møller 2010). The structure of the VAR is the following:

$$
X_{t}=\Psi+\Phi D_{t}+\Gamma T r_{t}+\sum_{i=1}^{p} A_{i} X_{t-i}+u_{t},
$$

where $X_{t}=\left[\begin{array}{lllll}F_{t} & G_{t} & C_{t} & Y_{t}\end{array}\right]^{\prime}$ is the vector of endogenous variables. In alternative specifications, we replace government spending with a measure of tax revenues net of transfers, and we replace private consumption with private investment. Our baseline specification includes a constant, a linear trend $T r_{t}$, and a crises dummy $D_{t}$ which equals 1 during the recent financial crises and zero otherwise. $u_{t}=\left[\begin{array}{llll}f_{t} & g_{t} & c_{t} & y_{t}\end{array}\right]^{\prime}$ is the vector of reduced-form residuals with variance-covariance matrix $E u_{t} u_{t}^{\prime}=V$. As Denmark is a small open economy, we impose the assumption that foreign tradeweighted GDP, $F_{t}$, is exogenous with respect to the domestic variables. We verify that this exogeneity assumption is in fact satisfied by performing an F-test of the null hypothesis that the three (lagged) domestic variables can be excluded from the regression equation for $F_{t}$ against the alternative that the exclusion restrictions are not satisfied. The p-value for this test is 0.404 , implying that we fail to reject the null hypothesis of block exogeneity. This validates our assumption.

The inclusion of foreign output as an exogenous variable represents one of the two important differences between our specification and the seminal VAR-model of Blanchard and Perotti (2002). We can think of our model as a small open economy version of their model. The second difference is that we have excluded taxes from our baseline specification, and instead include private consumption. As discussed by Blanchard and Perotti (2002), the structural VAR model favours a view of fiscal policy as working primarily through the demand side of the economy. While this seems a reasonable assumption for government spending, we believe it provides only a partial account of how changes in taxes affect the economy. Changes in income taxes, for example, are likely to affect the economy's supply side through changes in labor supply as well as the demand side via a change in disposable income. Moreover, Mertens and Ravn (2013) present a convincing critique of the method used to compute the automatic elasticity of tax revenues with respect to changes in output, which plays a key role in the identification strategy of the SVAR approach. ${ }^{5}$ For these reasons, we have decided to follow Ravn et al. (2012) and exclude taxes from our baseline specification, although we do study the effects of tax changes separately in an SVAR model in Section 4. The inclusion of private consumption in the list of endogenous

\footnotetext{
${ }^{5}$ Importantly, the same critique does not apply to the automatic elasticity of government spending with respect to output.
} 
variables follows a large number of recent papers in the SVAR tradition, including Monacelli and Perotti $(2008,2010)$ and Ravn et al. (2012). ${ }^{6}$ This allows us to study more closely the response of the private sector to changes in government spending.

We have tested for trend-stationarity of all the variables used. The test results are presented in Table 3 in the Appendix A. Using the stationarity test of Kwiatkowski et al. (1992), we fail to reject the null hypothesis of trend-stationarity at the $5 \%$ level for all variables, indicating that the data does not show signs of a unit root. We also apply an augmented Dickey and Fuller (1979) test. In this case, we can reject the null hypothesis of a unit root at the $5 \%$ level for $C_{t}$ and $F_{t}$, whereas we fail to reject the null at the $5 \%$ level for two of the four variables $\left(Y_{t}, G_{t}\right)$ in our baseline specification. Due to the well-known problems of low power of unit root tests in short samples, we take the test results as evidence that our assumption of trend-stationarity is not rejected by the data. We therefore decide to proceed using data in log-levels, which ensures consistent parameter estimates (Hamilton 1994), and including a deterministic trend in the regression. As in Blanchard and Perotti (2002), we also perform the analysis with the data in log-differences as a robustness check, allowing instead for a stochastic trend.

We also need to choose which number of lags $p$ of the endogenous variables to include. Table 4 in the Appendix A displays a number of tests and information criteria, to which we look for guidance on this choice. The three information criteria all point towards a low number of lags; 1 or 2 . The vector Portmanteau test also favors the use of only $1 \mathrm{lag}$, while the vector test for normality of the residuals favors a specification with a high number of lags (although just barely so, as all p-values are very low). Finally, the likelihood ratio tests fail to reject that $p$ lags are sufficient when $p$ is between 1 and 4 , but not when $p$ is 5 or 6 . Thus, while the data does not speak with a single voice on this issue, a choice of $p=2$ lags seems a reasonable compromise for our baseline specification. We later change the number of lags as a robustness check.

\subsection{The Data}

Our dataset includes quarterly national accounts data spanning the sample from 1983:Q1 to 2011:Q2. We choose 1983 as the first year in our sample, since a regime shift occured in 1982 when Denmark adopted a fixed exchange rate and put an end to a series of devaluations of its currency during the 1970's. ${ }^{7}$ We include a dummy for the recent crises, which equals 1 from 2008:Q4 onwards, and zero otherwise. While the recent crisis may not represent a regime shift, we consider it a time of unusual circumstances, which justifies the use of a dummy variable. For the domestic variables, we use national accounts data from Danmarks Nationalbank's MONA database. We obtain GDP data for Sweden and Germany from the OECD.

\footnotetext{
${ }^{6}$ Indeed, Blanchard and Perotti (2002) also present evidence from a specification in which private consumption is included along with government spending, taxes, and output.

${ }^{7}$ Moreover, beginning in early 1983, an automatic indexation of wages and transfers to the rate of inflation was suspended. This is likely to have played an important role in bringing down the inflation rate.
} 


\subsection{Identification Strategy}

As already mentioned, our identification strategy follows the approach of Blanchard and Perotti (2002). They argue that it takes more than a quarter for fiscal policymakers to realize that a shock has hit the economy, decide on the appropriate response of fiscal policy, pass the relevant legislation, and implement the fiscal measures in practice. Thus, using quarterly data, there can be no within-period discretionary response of government spending to economic shocks, so any simultaneous reaction of government spending to output or other variables must be due to automatic effects. These automatic effects can then be estimated outside the system. More specifically, we set up the following system of equations, which is essentially an open-economy version of that in Blanchard and Perotti (2002); except that we exclude taxes and instead include private consumption:

$$
\begin{gathered}
f_{t}=a_{1} g_{t}+a_{2} c_{t}+a_{3} y_{t}+e_{t}^{f}, \\
g_{t}=b_{1} f_{t}+b_{2} c_{t}+b_{3} y_{t}+e_{t}^{g}, \\
c_{t}=c_{1} f_{t}+c_{2} g_{t}+c_{3} y_{t}+e_{t}^{c}, \\
y_{t}=d_{1} f_{t}+d_{2} g_{t}+d_{3} c_{t}+e_{t}^{y} .
\end{gathered}
$$

As mentioned above, $u_{t}=\left[\begin{array}{llll}f_{t} & g_{t} & c_{t} & y_{t}\end{array}\right]^{\prime}$ contains the reduced-form residuals from the VAR regression, while $\varepsilon_{t}=\left[\begin{array}{llll}e_{t}^{f} & e_{t}^{g} & e_{t}^{c} & e_{t}^{y}\end{array}\right]^{\prime}$ is the vector of orthogonalized, structural innovations to $F_{t}, G_{t}, C_{t}$, and $Y_{t}$, respectively. These two vectors are related in the following way:

$$
u_{t}=C \varepsilon_{t}, \quad C C^{\prime}=V,
$$

where $V$ is the variance-covariance matrix of the residuals, as noted above. We need to impose identifying restrictions that allow us to pin down uniquely the matrix $\mathrm{C}$, as this enables us to back out the structural innovations and compute meaningful impulse responses.

In the system of equations above, (5) states that unexpected movements in domestic GDP $\left(y_{t}\right)$ within a quarter can arise due to unexpected movements in foreign GDP $\left(f_{t}\right)$, unexpected movements in private $\left(c_{t}\right)$ or public consumption $\left(g_{t}\right)$, or structural shocks to output $\left(e_{t}^{y}\right)$. The interpretation of the other equations is similar. Given our assumption that foreign GDP is exogenous with respect to the domestic variables, we impose that $a_{1}=a_{2}=a_{3}=0$. Moreover, we assume that if there is any automatic effect on public spending of changes in foreign output, this effect occurs via the effect of foreign output on domestic output, so that $b_{1}=0$. Similarly, we assume that changes in private consumption does not cause automatic changes in government spending on top of a potential effect through output, i.e. that $b_{2}=0$.

The parameter $b_{3}$ measures the automatic effects that changes in output might have on public spending within a quarter. As discussed by Caldara and Kamps (2012), 
as well as in Subsection 3.2 of the present paper, setting a value for this parameter is not innocuous, as this has substantial effects on the estimated impact multiplier of an increase in public spending. In the literature, this parameter is typically set to zero; see e.g. Blanchard and Perotti (2002), Monacelli and Perotti (2008, 2010), or Ravn et al. (2012). An exception is Bergman and Hutchison (2010), who set the parameter to -0.2 for Denmark, based on a study by Giorno et al. (1995). That elasticity is found by computing the elasticity of unemployment-related expenditures to output, and multiplying by the share of unemployment-related expenditures to total government expenditure. However, unemployment-related expenditures are not included in the measure of public consumption used in the present study. In general, our measure of government spending should not include any components that vary automatically with output within a quarter. Caldara and Kamps (2012) argue that $b_{3}$ is likely to be positive, citing evidence by, among others, Lane (2003) that government consumption tends to be pro-cyclical in most OECD countries, including Denmark. This result is obtained at the annual level, however, and does not necessarily carry over to quarterly data. In our baseline scenario, we therefore follow the literature and set $b_{3}=0$, while we use different values for this parameter as a robustness check.

To pin down the parameters in the final two equations, we need to take a stand on whether private consumption or output is determined first. We assume that private consumption affects output within a quarter, but not the other way around; i.e. $c_{3}=0$ but $d_{3} \neq 0$. It should be emphasized that all our results remain unchanged if instead we assume $c_{3} \neq 0$ and $d_{3}=0$. We then construct the cyclically adjusted government spending residuals; $g_{t}^{\prime}=g_{t}-b_{3} y_{t}\left(=g_{t}\right.$ when we set $\left.b_{3}=0\right)$. These residuals are uncorrelated with the structural innovations to output and consumption, $e_{t}^{y}$ and $e_{t}^{c}$, allowing us to use them as instruments for $g_{t}$ in regressions of $c_{t}$ and $y_{t}$ on the right-hand side variables in Eqs. 4 and 5. Likewise, we need the structural innovations to foreign output, $e_{t}^{f}$, to be uncorrelated with $e_{t}^{y}$ and $e_{t}^{c}$. This is ensured by the inclusion of US GDP as an exogenous variable in the original VAR, as this variable controls for global shocks such as productivity shocks that are likely to affect both the foreign and the domestic economy. Hence, we first estimate $c_{1}$ and $c_{2}$ by regressing $c_{t}$ on $e_{t}^{f}$ and $g_{t}$, with $g_{t}^{\prime}$ as instrument for $g_{t}{ }^{8} \mathrm{We}$ then estimate $d_{1}, d_{2}$, and $d_{3}$ by regressing $y_{t}$ on $e_{t}^{f}, c_{t}$ and $g_{t}$, again using $g_{t}^{\prime}$ as an instrument. ${ }^{9}$

Having pinned down all parameters, it is straightforward to solve the system above for the structural shocks as functions of the reduced-form residuals obtained from the VAR and the estimated coefficients. Moreover, we can compute the coefficients in the matrix $\mathrm{C}$ from these parameters, allowing us to obtain the impact effects on the endogenous variables of an orthogonalized, structural innovation to one of these

\footnotetext{
${ }^{8}$ Recall that $e_{t}^{f}=f_{t}$.

${ }^{9}$ Of course, when we set $b_{3}=0$ so that $g_{t}^{\prime}=g_{t}$, the use of $g_{t}^{\prime}$ as an instrument in practice becomes redundant. On the other hand, when we set $b_{3} \neq 0$, or in the specification with taxes instead of government spending, this step becomes relevant.
} 
variables, which is needed for impulse responses. The impact effects of a shock to government spending are given by:

$$
\begin{gathered}
f_{t}=0, \\
g_{t}=\left[1+b_{3} \frac{d_{2}+c_{2} d_{3}}{1-b_{3} d_{2}-b_{3} c_{2} d_{3}}\right] e_{t}^{g}, \\
c_{t}=\left[c_{2}+\frac{\left(b_{3} c_{2}\right)\left(d_{2}+c_{2} d_{3}\right)}{1-b_{3} d_{2}-b_{3} c_{2} d_{3}}\right] e_{t}^{g}, \\
y_{t}=\frac{d_{2}+c_{2} d_{3}}{1-b_{3} d_{2}-b_{3} c_{2} d_{3}} e_{t}^{g} .
\end{gathered}
$$

It should be noted that when we set the elasticity of government spending to output $b_{3}=0$, the identification strategy collapses to a standard Choleski decomposition with government spending ordered before consumption and output. However, we use the structural identification scheme outlined above for at least two reasons: First, it allows us to replace government spending with taxes, for which the output elasticity is surely not zero. Second, we are able to relax the assumption of a zero output elasticity of government spending as a robustness check. As described in Subsection 3.2, it turns out that our results are very sensitive to this parameter.

\section{The Effects of Government Spending}

In this section, we present and discuss our results about the effects of government spending, including a number of robustness checks. We first look at orthogonalized impulse responses to a shock to government spending. Given the exogeneity of the foreign variable, it is not affected by this shock, so we report impulse responses only for the domestic variables. Consider first our baseline scenario with variables in log-levels, as depicted in Fig. 1.

As the figure makes clear, the increase in government spending is quite persistent, remaining significantly above zero for almost 5 years after the shock. However, the effect of the fiscal stimulus on output appears to die out faster. After a fairly large initial increase, output quickly reverts back to its original level. The reaction of output is significant during the first 2 years (except for the second and fourth quarter after the shock).

We have converted the impulse responses in Fig. 1 so that the fiscal multiplier is directly observable. The impact multiplier of government spending on output is 1.07 , implying that a 1 DKK rise in government spending causes an immediate increase in GDP of 1.07 DKK. This multiplier is well within the interval 0.8-1.5 highlighted by Ramey (2011). However, we observe that the multiplier quickly decreases. A year after the shock, the multiplier is around 0.6, and after two years the multiplier becomes insignificant. The government spending multiplier is above 1 only on impact, i.e. in the same quarter in which government spending is increased. These findings are in line with the theoretical arguments in the introduction. In the short run, fiscal stimulus is quite effective in Denmark, as prices are sticky, and neither 

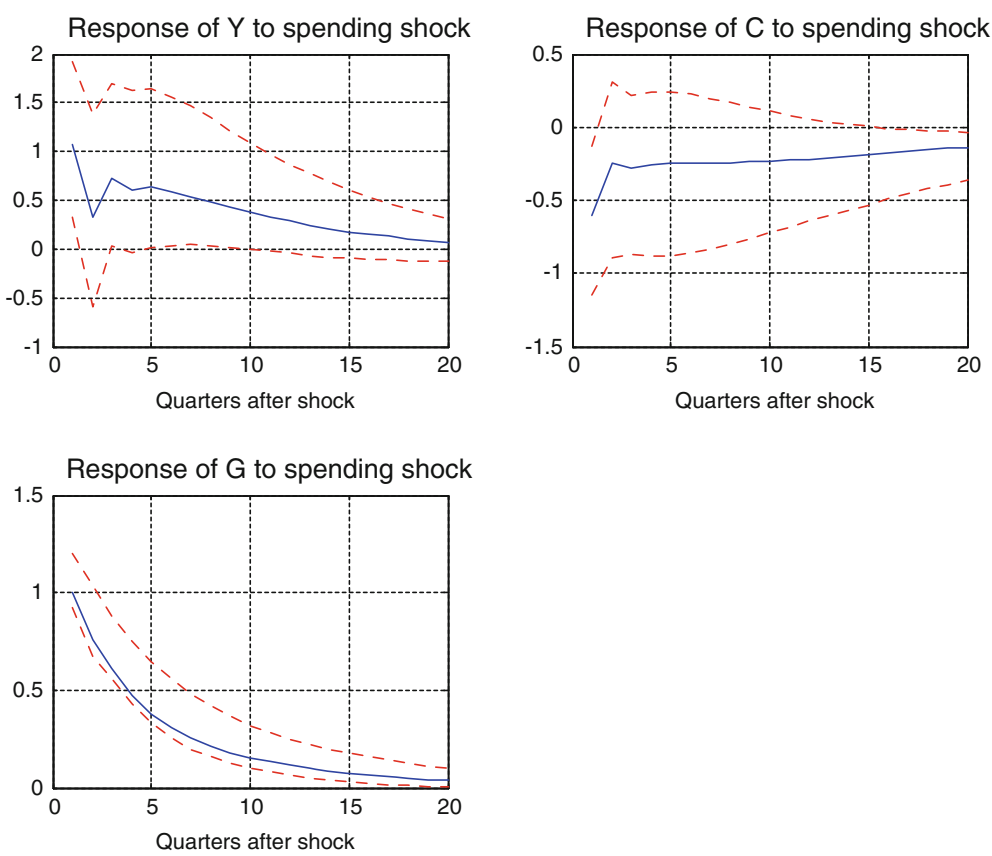

Fig. 1 The dynamic response of each variable to a unit shock to government spending. Dotted lines indicate bootstrapped $90 \%$ error bands. The error bands are computed using Hall's (1992) bootstrap method with 10,000 replications

the nominal interest rate nor the nominal exchange rate can adjust. However, as soon as prices start to adjust, the effects of fiscal stimulus die out, as the Danish economy loses competitiveness against its trading partners. The economic impact of fiscal stimulus seems to peter out as the stimulus itself is removed.

Our results are consistent with other recent, empirical findings about the effects of fiscal policy in small open economies. Ilzetzki et al. (2013) study a sample of 44 countries, and find a government spending multiplier of around 1.4 in economies operating under fixed exchange rates, while the multiplier is much lower (and significantly so) in countries with floating exchange rate regimes. ${ }^{10}$ These authors furthermore find empirical support for the importance of the interest rate channel, as they report an increase in the nominal interest rate under flexible exchange rates. Corsetti et al. (2012) study the effects of fiscal policy in 17 OECD countries, and also find a significantly higher fiscal multiplier under fixed exchange rates. They find an estimated multiplier of 0.6 under fixed exchange rates, and around zero under floating rates. On the other hand, they find no direct evidence in favor of the interest rate effect. Beetsma and Giuliodori (2011) find a fiscal multiplier around 1.2 for a sample of 14 member countries of the European Union, although for the most open

\footnotetext{
${ }^{10}$ It should be noted that the multiplier reported by Ilzetzki et al. (2013) is a cumulative multiplier, measuring the accumulated increase in output over a number of quarters. The impact multiplier is substantially smaller in their study.
} 
economies among these, including Denmark, the multiplier is found to be slightly below 1. This highlights the importance of the leakage effect, which has also been emphasized by Zhang and Zhang (2011).

Nakamura and Steinsson (2013) estimate a fiscal multiplier of around 1.5 based on US data at the state and regional level. The idea is that each state represents a small, open economy with a fixed exchange rate relative to its neighbour states. What they report is the so-called open economy relative multiplier, which measures the change in output in one state relative to other states when government spending in that state is increased. As such, their result is not directly comparable to ours. Finally, Bergman and Hutchison (2010) study the effects of fiscal policy in Denmark in a setup related to ours, but with a sample from 1971-2000, and with specific focus on the effects of the Danish fiscal contraction in the mid-1980's. Our results are in general consistent with their findings, although some differences arise due to the use of different model specifications and different sample periods.

Somewhat surprisingly, we observe a significant drop in consumption on impact, although from the second quarter onwards, the reaction of consumption is small and insignificant. Most studies based on the approach of Blanchard and Perotti (2002) tend to report an increase in consumption after a shock to government spending in various countries (see e.g. Gali et al. (2007) or Ravn et al. (2012)). Our finding of a drop in consumption is instead more in line with studies using the approach of Ramey and Shapiro (1998). ${ }^{11}$ The initial drop in consumption is robust to the choice of lags, as discussed below, and it also does not change if we order $C_{t}$ after $Y_{t}$ in the VAR, i.e. if we assume that $c_{3} \neq 0$ and $d_{3}=0$. On the other hand, the drop is always very short-lived. Nevertheless, it suggests that Danish households at least to a certain extent act in a Ricardian manner in response to an increase in government spending. Higher government spending today implies higher taxes at some point in the future if the government is to satisfy its intertemporal budget constraint.

We can think of at least two reasons why Danish households may be 'more Ricardian' than households in other countries. First, they have access to very wellfunctioning financial markets. Following financial market deregulation in the early 1990's Danish home owners have had easy access to mortgage equity withdrawal. According to Duygan-Bump and Grant (2009), the share of Danish households with debt $(88 \%)$ is far above the average for a selection of 10 EU countries $(54 \%)$. This is true not only for mortgage debt, but also for other debt (59\% in Denmark versus an average of $28 \%$ ). This indicates that Danish households are better able to smooth consumption than households in other countries, facilitating a Ricardian response of consumption. Second, during the last two decades, fiscal policy in Denmark has been very transparent, with medium-term fiscal plans supported by a large political majority in place to ensure fiscal sustainability. This implies that fiscal stimulus in a given year must be met with tighter fiscal policy in a not too distant future to stay in line

\footnotetext{
${ }^{11}$ In particular, it may seem puzzling that the government spending multiplier is above 1 despite the drop in consumption. In results not reported, we find that this is explained by an increase in private investment on impact. The increase in investment is large on impact, after which it quickly reverts back around zero. In effect, the impulse response of investment mirrors that of private consumption.
} 
with medium-term objectives. There is good reason to believe that this is anticipated by the public, as plans for future cutbacks are often revealed along with the announcement of the stimulus itself. Moreover, a recent study by Jappelli (2010) rates the economic literacy rate in Denmark 6th out of 55 countries studies. We believe these observations rationalize the observed response of private consumption in Denmark.

\subsection{Subsample Stability}

While much of the debate about the effects of fiscal policy has centered around the size of the government spending multiplier, it is important to note that this multiplier is far from constant. Instead, it is likely to vary substantially over time and across different economic situations. For the US, for example, Perotti (2005) and Bilbiie et al. (2008) have demonstrated that the fiscal multiplier has been declining over time. Bilbiie et al. (2008) argue that this can be explained by two factors: Increased assetmarket participation by households, and a more active monetary policy since the beginning of the 1980's. Increased asset-market participation allows households to smooth consumption over time, lowering their sensitivity to shocks affecting current income, such as fiscal policy shocks. A more active stance of monetary policy implies a stronger interest rate reaction to the inflationary effects of an expansionary fiscal policy, inducing an increase in the real interest rate which dampens the effect on economic activity.

To evaluate how the fiscal multiplier in Denmark has evolved over time, we split the sample into three different subsamples, roughly corresponding to three different decades. Table 1 shows the impact multiplier for various subsamples, i.e. the increase in output (in DKK) in the same quarter as government spending is increased by 1 DKK. As the table illustrates, the government spending multiplier for Denmark has been fairly constant over time. The impact multiplier has remained relatively close to 1 during each decade, in line with our estimate of 1.1 for the entire sample. The confidence intervals are very wide, however, in large part because of the short subsamples with only around 40 quarterly observations each.

The size of the government spending multiplier is likely to depend on the evolution of the monetary policy regime as well as the degree of openess of the economy. While

Table 1 Impact multipliers for different subsamples

\begin{tabular}{llc}
\hline Subsample & Multiplier & $90 \%$ Confidence Interval \\
\hline $1983-2011$ & 1.07 & {$[0.33 ; 1.93]$} \\
$1983-1990$ & 1.04 & {$[-0.03 ; 2.76]$} \\
$1991-2000$ & 0.89 & {$[-0.23 ; 2.39]$} \\
$2001-2011$ & 1.18 & {$[-0.25 ; 2.91]$} \\
\hline
\end{tabular}

The crisis dummy is included in the regression for 1983-2011, but not in the regression for 2001-2011. The confidence intervals are computed using the bootstrap method of Hall (1992) with 10,000 replications. Note that because confidence intervals are bootstrapped, they are not necessarily symmetric. All specifications include a deterministic trend 
Denmark committed to a fixed exchange rate in 1982, credibility over the currency peg was not gained overnight. As a result, until well into the 1980's fiscal expansions were likely to be met by expectations of higher inflation and higher interest rates, tending to suppress the effectiveness of fiscal policy. Instead, during the last two decades Denmark has had a credibly fixed exchange rate as well as low and stable inflation and sound public finances. All else equal, this points to an increase in the effectiveness of fiscal policy, as credibility over the currency peg is a key assumption in theoretical models of fiscal policy in open economies with fixed exchange rates. On the other hand, the share of imports to GDP has approximately doubled over the same period. This suggest a substantial increase in the leakage effect, which would tend to reduce the multiplier. In addition, as for the US, household's asset market participation is likely to have increased over time in Denmark, not least because of financial market deregulation in the early 1990's. The fact that the multiplier has remained roughly constant suggests that the effect of increased credibility about the fixed exchange has been offset by the increased openness to international trade.

In sum, while our results differ from those of Perotti (2005) and Bilbiie et al. (2008) for the US, there is a reason for this discrepancy. Furthermore, there is no reason to believe that the fiscal multiplier will increase in the future, as Denmark's fixed exchange rate is now surrounded by a very high credibility, as evidenced by the low interest rate spread against Germany. The scope for obtaining larger effects of fiscal policy thus seems to have been exhausted. On the other hand, if the share of imports to GDP continues to rise in the future, this may exert downward pressure on the multiplier by further strengthening the leakage effect.

\subsection{Robustness}

While the previous subsection offered a first glance at the robustness of the estimated fiscal multiplier, we now investigate this issue in more detail. We display impulse responses only when these differ substantially from those in Fig. 1, although all results are available upon request.

First, we allow for quarterly dummies, as suggested by Blanchard and Perotti (2002). The results from this exercise are practically identical to those described above. Next, we exclude the crisis dummy from our baseline specification. This also does not change our results in any fundamental way, although the impact multiplier is slightly larger in this case.

We have investigated the sensitivity of our results to the number of lags in the VAR, which we set to 2 in our baseline estimation. With 1 lag, the impact multiplier rises to around 1.3, but the impulse responses do not change much. With 3 or 4 lags, the response of output no longer peaks on impact, but instead after 3 quarters, reaching around 1.5 in both cases. The reason is that after an initial drop, consumption increases during several quarters; significantly so for a few quarters in the specification with 4 lags. This implies that the results from these specifications are somewhat more similar to those obtained by Blanchard and Perotti (2002) for the US. Indeed, Blanchard and Perotti use 4 lags in their study, although they do not report tests or information criteria to support this choice. Thus, while our data favours the use of a model with a low number of lags, as already discussed, the fact that our results come 
closer to mimicking those of Blanchard and Perotti when we imitate their choice of lags is an interesting finding.

The results above were obtained with data in log-levels. Following Blanchard and Perotti (2002), we perform a similar analysis allowing for a stochastic trend in the data instead of a deterministic trend. With data in log-differences, the VAR regression and the structural identification strategy are the same, with the exception that the linear trend $T r_{t}$ is removed from the VAR. We display the impulse responses from this analysis in Fig. 4 in the Appendix A. The effect on output peaks after 3 quarters with a significantly positive multiplier of 1.22 , i.e. slightly higher than in the model with a deterministic trend. As for consumption, we still observe a significant drop on impact, but now the response turns positive in the next few quarters. In sum, the results from this exercise give rise to roughly similar conclusions as the baseline specification, although the response of output is insignificant most of the time.

Finally, we want to evaluate the consequences of different assumptions in our identification scheme. In particular, we consider the robustness of the estimated impact multiplier of government spending with respect to different values of the elasticity of government spending to output within the quarter $\left(b_{3}\right)$, which was set to zero in our baseline specification. As demonstrated by Caldara and Kamps (2012), this parameter has a heavy influence on results based on US data. This turns out also to be the case for our study of Denmark. Figure 5 in the Appendix A shows how our estimate for the impact multiplier changes when we vary the value of $b_{3}$. As the figure illustrates, the impact multiplier is highly sensible to the value of this parameter. For example, if $b_{3}$ is allowed to take on a modest value of 0.1 , the impact multiplier drops to 0.16 , compared to our baseline estimate of 1.07 . Similarly, if we set $b_{3}$ to -0.1 , the multiplier is as high as $1.94 .^{12}$ The intuitive explanation for this finding is the following: If for example the automatic elasticity of government spending to output is negative $\left(b_{3}<0\right)$, the increase in output brought about by a positive shock to government spending will in itself induce a fall in government spending, all else equal. As a result, the eventual increase in government spending will be small, while the increase in output is the same (abstracting from a small second-round effect). Hence, the estimated multiplier will be larger.

We are therefore able to confirm the results of Caldara and Kamps (2012); in fact, the sensitivity of the multiplier seems even bigger in our case. The large sensitivity of the results is an obvious shortcoming of the identification strategy of Blanchard and Perotti (2002) that has until recently largely been ignored in the literature. As discussed in Subsection 2.2, the parameter $b_{3}$ is likely to be close to zero, but as we have demonstrated, even small deviations from zero lead to substantially different results. This indicates that our estimated multiplier should be interpreted with care.

\footnotetext{
${ }^{12}$ In results not reported, we observe that consumption rises on impact when $b_{3}$ is sufficiently low. In fact, we find that this explains the divergence between the negative consumption response in the present study and the positive response obtained by Bergman and Hutchison (2010), who set $b_{3}=-0.2$.
} 


\section{Effects of Taxes}

As discussed in Section 2, the SVAR model likely neglects important macroeconomic effects of changes in tax policy. Nevertheless, in this section we attempt to gain at least some insight on the effects of taxes by including them in our SVAR, although these results should therefore not be interpreted as a complete account of the effects of tax changes.

We use a measure of tax revenues net of transfers. We add direct taxes (including corporate taxes and capital gains taxes), indirect taxes, and social contributions, and subtract transfers to households. We then insert taxes $\left(T_{t}\right)$ instead of government spending $\left(G_{t}\right)$ in our baseline VAR as presented in (1) with two lags, a constant, a deterministic trend, and with the crises dummy included in the block of exogenous variables.

The structural system is essentially the same as the one presented in Subsection 2.2, with taxes replacing government spending. We also keep the same identifying assumptions. The only difference is related to the elasticity of the tax revenue with respect to changes in output, which we denote $b_{3}^{T}$. In contrast to the specification with government spending, this elasticity is now unlikely to be zero, as a rise in GDP will lead to an automatic increase in the tax base and in turn, the tax revenue. In order to pin down $b_{3}^{T}$, we decompose the total tax revenue into different types of taxes (income taxes, corporate taxes, etc.). We then compute the elasticity of each type of tax with respect to changes in output, and weigh these together to obtain a measure of the elasticity of total tax revenues. The method is described in detail in Appendix B. We arrive at a value of $b_{3}^{T}=2.09$.

The impulse responses to an increase in the tax revenue are shown in Fig. 2. As illustrated, an increase in taxes leads to a drop in output and consumption, although the latter is not significant. The estimated tax multiplier is 0.76 on impact, which is smaller than the government spending multiplier. This suggests that government spending is a more effective tool for short-term stabilization of the economy than tax changes. To some extent, this may reflect the focus of the SVAR approach on the demand side effects of economic policy. A number of recent studies that pay more attention also to supply-side effects have challenged this result, and tend to find that the tax multiplier is at least as large as the spending multiplier (see Alesina and Ardagna (2010), Romer and Romer (2010) or Mertens and Ravn (2013)).

We further observe that output quickly returns to its initial level, as the response is numerically quite small from the second quarter after the shock onwards. Due to the drop in output and the resulting drop in the tax base, tax revenues quickly return to zero. ${ }^{13}$ Finally, we explore the sensitivity of the tax multiplier to the value of the parameter $b_{3}^{T}$. It turns out that the tax multiplier is much more robust than the government spending multiplier, in line with the findings of Caldara and Kamps (2012). In particular, if we increase $b_{3}^{T}$ to 2.5 , the estimated impact multiplier increases only to 0.79 . If instead we set $b_{3}^{T}=1.5$, the multiplier drops to 0.63 .

\footnotetext{
${ }^{13}$ Note that the shock to tax revenues has been normalized to 1 , so as to facilitate comparison with the shock to government spending. The response of tax revenues, however, is smaller than 1 already on impact, as the rise in taxes implies a drop in output, and hence in the tax base.
} 

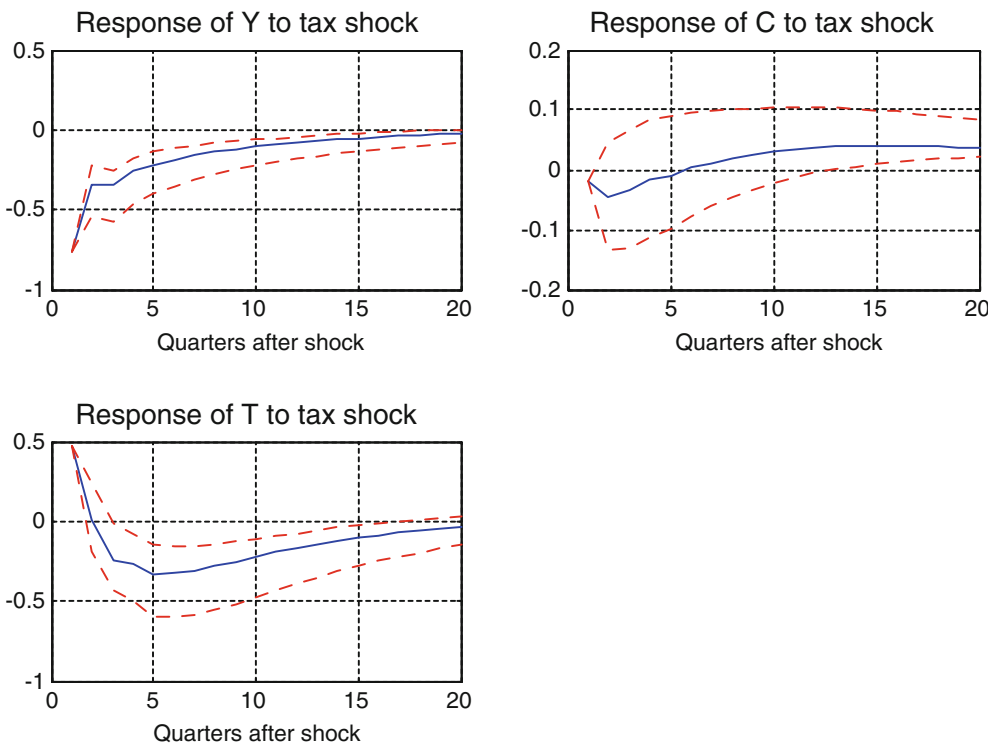

Fig. 2 The effects of an increase in net tax revenues

\section{What Drives the Danish Business Cycle?}

In this section, we use our estimated, structural VAR model to decompose recent business cycle fluctuations in Denmark. We first undertake a historical decomposition to shed light on the contribution of various shocks to fluctuations in output. Subsequently, we perform a variance decomposition of the endogenous variation in our VAR-model.

\subsection{Historical Decompositions}

We perform the historical decomposition by simulating the VAR regression in Eq. 1 and in each step adding the structural shocks of the model one at a time. We use the first two quarters in our sample to initiate the simulation. By comparing the resulting simulated series to the actual, observed variables, we can isolate, for example, the contribution of exogenous changes in government spending to deviations of output from trend, as described by Lindé (2003). This is done by 'turning off' all other structural shocks than those to $e_{t}^{g}$; i.e., simply setting them to zero. Figure 3 shows the deviations of output from its simulated trend over the course of our sample, as well as the share explained by structural shocks to government spending. The share of other shocks is illustrated in Figs. 6 and 7 in the Appendix A. As Fig. 3 illustrates, shocks to government spending only account for a small share of output fluctuations. Moreover, it is noteworthy that there is little evidence of systematic, countercyclical fiscal policy; at least as measured by government spending. In particular, the stance of fiscal policy appears to have been 'too tight' during the recession in the late 1980's and early 1990's. Likewise, during the economic boom in the second half of 


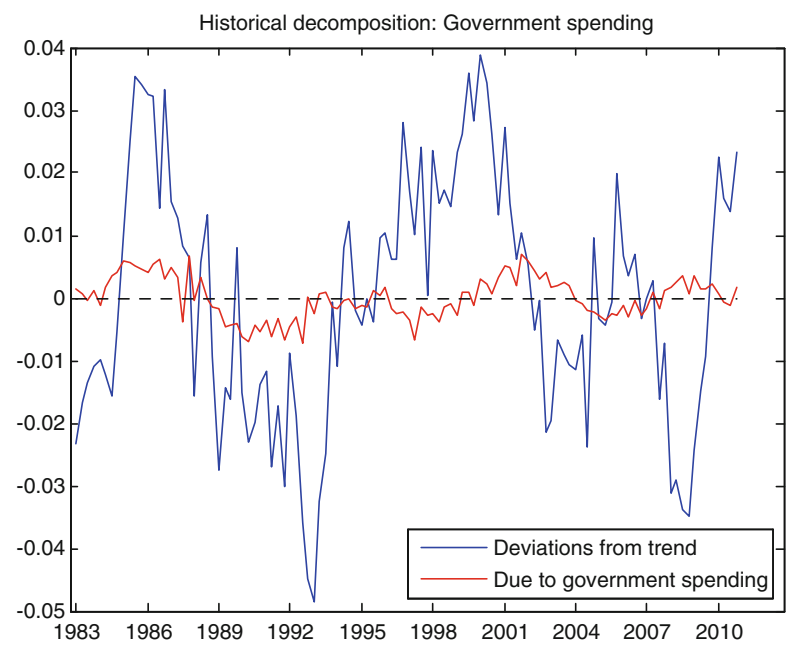

Fig. 3 Historical decomposition. The blue line shows deviations in output growth relative to its trend growth. The red line shows the share explained by deviations in the growth rate of government spending relative to its trend

the 1990's, the growth rate of government spending was not reduced relative to its historical trend. ${ }^{14}$

Furthermore, Fig. 6 in the Appendix A shows the contribution to the Danish business cycle from business cycle movements in Denmark's two most important trading partners, Germany and Sweden. As is to be expected for a small open economy, such movements have a substantial impact on the Danish business cycle. For example, the post-reunification boom in Germany in 1990-91 can be clearly identified, although its effect on the Danish economy seems to be dominated by a strong recession in Denmark. Figure 6 shows the contribution that can be attributed to domestic shocks other than government spending shocks, i.e. fundamental shocks to $Y_{t}$ or $C_{t}$. These shocks account for an important share of the movements in GDP, indicating that the Danish business cycle is not entirely driven by foreign shocks, despite being a small open economy. A similar result is obtained by Dam and Linaa (2005), who estimate a DSGE model for Denmark, and report that the main driver of output variations, especially in the long run, is stochastic movements in the labor supply of Danish households. ${ }^{15}$ An interesting observation from Fig. 6 is that at least since the

\footnotetext{
${ }^{14}$ The figure also suggests that fiscal policy was not tightened sufficiently in the years leading up to the recent crisis. As seen from Fig. 6 in the Appendix A that Denmark's trading partners exerted a strong, positive impact on the Danish economy in 2006-07. Moreover, a recent study by Ravn (2012) suggests that, as a consequence of Denmark's fixed exchange rate towards the euro, the Danish interest rate was substantially lower than what would have been prescribed by a Taylor rule for Denmark in the years 20052007. These factors would have called for an even tighter stance of fiscal policy during these years than what can be observed from Fig. 3.

${ }^{15}$ Our SVAR-model is of course much more rudimentary, and in particular does not feature shocks to the labor supply. In our setup, however, such shocks are likely to show up as fundamental shocks to $Y_{t}$; or perhaps to $C_{t}$ through the consumption/labor decision of households.
} 
Table 2 Variance decomposition for output

\begin{tabular}{lllll}
\hline & $f_{t}$-shocks & $g_{t}$-shocks & $c_{t}$-shocks & $y_{t}$-shocks \\
\hline Business cycle freq. & 0.314 & 0.073 & 0.145 & 0.468 \\
All frequencies & 0.262 & 0.072 & 0.159 & 0.507 \\
\hline
\end{tabular}

beginning of the 1990's, the contribution of foreign shocks looks like a smoothed version of the actual deviations of output from its trend, suggesting that the Danish business cycle is fundamentally driven by the business cycle of its trading partners, with domestic shocks determining the high-frequency movements in Danish GDP, as illustrated by Fig. 7. This is in line with the results of Dam (2008), who shows that since the mid-1990's the Danish business cycle has been highly synchronized with business cycle movements in Germany and other Euro area countries.

\subsection{Variance Decompositions}

We can shed further light on the driving forces behind the Danish business cycle by examining the importance of each shock at various points of the frequency domain. We follow the variance decomposition method used by Altig et al. (2005), the details of which are outlined in Appendix C. This method allows us to decompose the variance of each of the four endogenous variables for any frequency $\omega$ in the frequency domain. In this way, we can investigate the relative importance of the four shocks at various frequency intervals.

Table 2 shows the variance decomposition for output. The first row describes how much of the variation in output at business cycle frequencies can be attributed to structural shocks to each of the four variables, while the second row shows the same for the entire frequency spectrum. Following Altig et al. (2005), we define business cycle frequencies as 8 to 32 quarters. The table reveals that shocks to government spending explain less than $10 \%$ of the variation in output at business cycle frequencies as well as over the entire frequency spectrum. This confirms that government spending has not played a very important role in driving the Danish business cycle. Furthermore, the table shows that shocks to output in Germany and Sweden are substantial contributors to output fluctuations, as are domestic shocks to output or private consumption.

\section{Conclusion}

We have presented an array of empirical findings about the effects of fiscal policy in Denmark that can broadly be summarized as follows: First, an increase in government spending has a rather large impact on output in the short run, with a fiscal multiplier around 1.1. However, the expansionary effects are short-lived, as the multiplier is above 1 only on impact, and drops to around 0.6 a year after the stimulus is injected. The response of output becomes insignificant after about two years. 
These results suggest that in the short run, the monetary accomodation effect under a fixed exchange rate outweighs the leakage effect following from a large degree of openness to trade. Second, as for the effect on consumption, our results tend to suggest that private consumption goes down after an increase in government spending. Third, an increase in taxes depresses economic activity, although the tax multiplier is smaller than the spending multiplier. Fourth, we demonstrate that shocks to government spending account for less than $10 \%$ of the movements in output over the business cycle. Finally, the estimated government spending multiplier is fairly constant over time, but quite sensitive to the assumed automatic elasticity of government spending to output.

A number of authors have used empirical results about fiscal policy to evaluate competing macroeconomic theories and models (Blanchard and Perotti 2002; Gali et al. 2007). As discussed by Blanchard and Perotti, for example, an increase in private consumption in response to a government spending shock is consistent with traditional, Keynesian models, in which a household's consumption is a function of its current income. This will tend to increase, depending on how the fiscal stimulus is financed. In contrast, a drop in consumption suggests that households behave in a Ricardian fashion, as assumed in standard neoclassical models such as the Real Business Cycle model, as well as in New-Keynesian models. In these models, consumption is instead determined by lifetime income, which goes down due to the increase in the present value of future tax payments. The results in the present paper seem to lend more support to the latter class of models, in which households display at least some degree of Ricardian behaviour, although the data does not allow us to draw any firm conclusions in this respect.

\section{Appendix A: Additional Tables and Figures}

Table 3 Unit root and stationarity tests

\begin{tabular}{llr}
\hline & Augmented Dickey-Fuller & KPSS \\
\hline Critical Value $(5 \%)$ & -3.45 & 0.15 \\
Test Statistics & & \\
$Y_{t}$ & -0.68 & 0.14 \\
$C_{t}$ & -4.05 & 0.08 \\
$G_{t}$ & -2.51 & 0.13 \\
$F_{t}$ & -4.53 & 0.14 \\
$T_{t}$ & -3.02 & 0.14 \\
\hline
\end{tabular}

All tests are done for the sample 1983Q1:2011Q2. With the Augmented Dickey-Fuller tests, each variable has a unit root under the null. We fail to reject the null for two of the four variables in our baseline model $\left(Y_{t}, G_{t}\right)$, as well as for $T_{t}$ used in the tax analysis. The ADF tests are computed with automatic lag selection based on the Akaike information criterion. With the KPSS test, each variable is trend-stationary under the null hypothesis. We fail to reject the null hypothesis for all five variables. The KPSS tests are done using a Bartlett kernel with automatic Andrews bandwidth selection 
Table 4 Specification tests for the VAR

\begin{tabular}{llllllr}
\hline \# of lags & Akaike & Schwartz & Hannan-Quinn & Portmanteau & Normality & Likelihood Ratio \\
\hline 1 & $\mathbf{- 3 7 . 1 3}$ & $\mathbf{- 3 6 . 5 3}$ & $\mathbf{- 3 6 . 8 9}$ & $\mathbf{2 1 3 . 4 4 ( 0 . 0 2 8 4 )}$ & $31.24(0.0001)$ & $\mathbf{7 . 4 5 ( \mathbf { 0 . 0 5 8 8 } )}$ \\
2 & -37.11 & -36.19 & -36.74 & $200.12(0.0172)$ & $31.74(0.0001)$ & $\mathbf{1 1 . 8 6 ( 0 . 0 6 5 2 )}$ \\
3 & -37.11 & -35.85 & -36.60 & $201.67(0.0011)$ & $38.05(0.0000)$ & $\mathbf{1 5 . 7 7 ( 0 . 0 7 1 9 )}$ \\
4 & -37.05 & -35.46 & -36.41 & $195.31(0.0001)$ & $37.50(0.0000)$ & $\mathbf{1 6 . 7 6 ( 0 . 1 5 8 8 )}$ \\
5 & -36.99 & -35.08 & -36.22 & $172.21(0.0002)$ & $\mathbf{2 6 . 0 4 ( 0 . 0 0 1 0 )}$ & $38.33(0.0008)$ \\
6 & -36.88 & -34.65 & -35.98 & $162.38(0.0000)$ & $\mathbf{2 6 . 0 5 ( 0 . 0 0 1 0})$ & $46.10(0.0003)$ \\
\hline
\end{tabular}

The first 3 columns simply report the information criteria. The last 3 columns report test statistics, with p-values in brackets. In each column, numbers in bold indicate the preferred specification

Response of $Y$ to spending shock

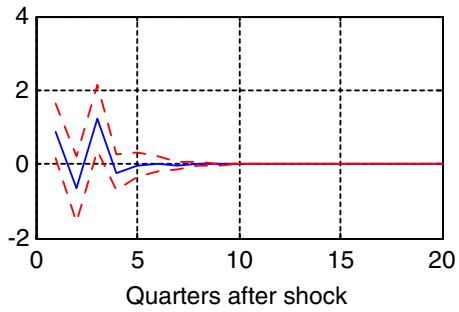

Response of $\mathrm{G}$ to spending shock

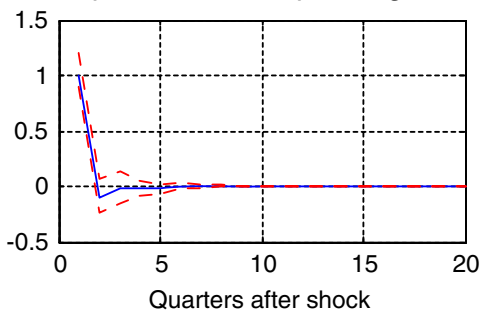

Response of $\mathrm{C}$ to spending shock

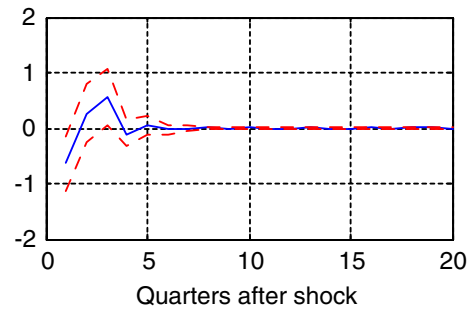

Fig. 4 The effects of a shock to government spending, specification with stochastic trend

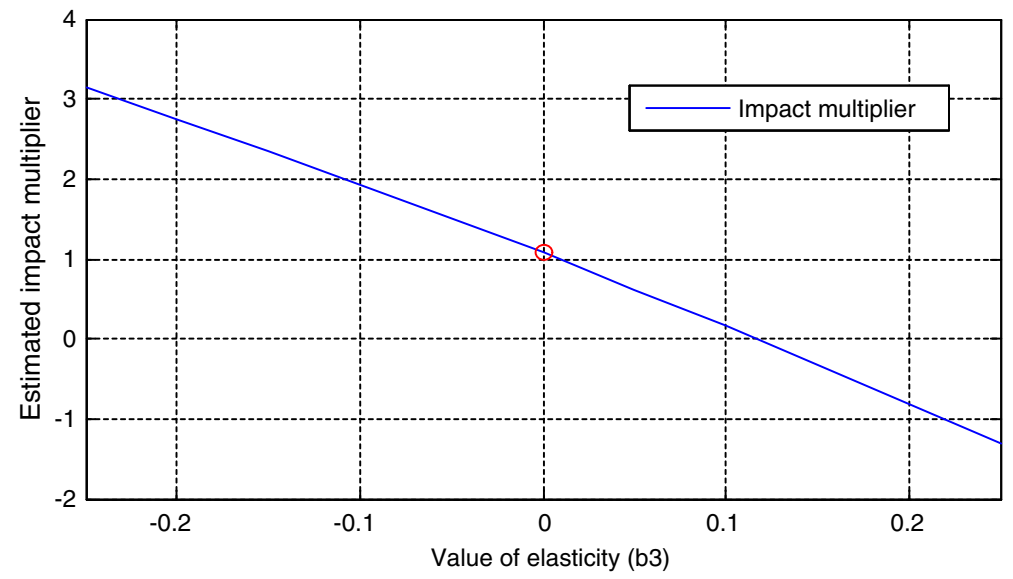

Fig. 5 The sensitivity of the estimated impact multiplier of government spending to the elasticity of government spending to output. The red dot indicates our baseline estimate of $b_{3}=0$ 
Historical decomposition: Trading partners

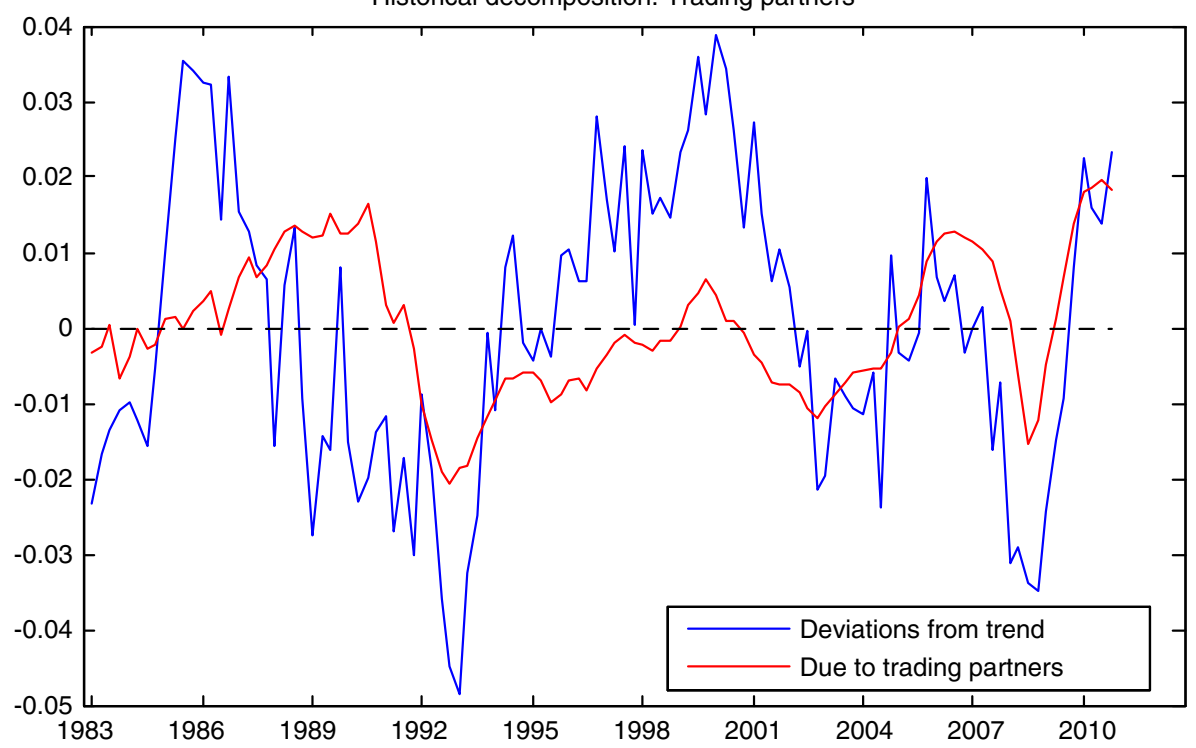

Fig. 6 Historical decomposition. The blue line shows deviations in output growth relative to its trend growth. The red line shows the share explained by deviations in the growth rate of $F_{t}$ relative to its trend

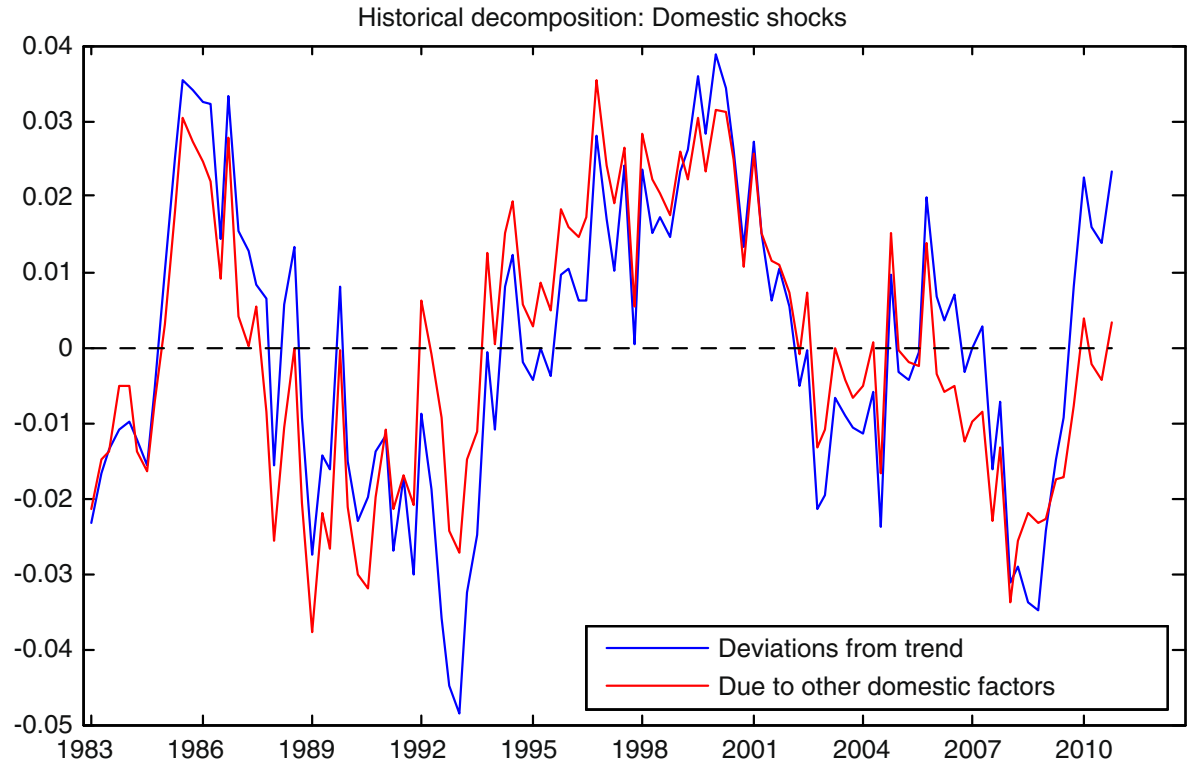

Fig. 7 Historical decomposition. The blue line shows deviations in output growth relative to its trend growth. The red line shows the share explained by deviations from trend in other domestic variables than government spending 


\section{Appendix B: Computing the Output Elasticity of Taxes}

This appendix provides a detailed account of how we obtain an estimate of the elasticity of taxes to changes in output, as employed in Section 4.

We decompose the total tax revenue into four categories: Income taxes, corporate taxes, indirect taxes, and social contributions. We then obtain the elasticity of each of these types of taxes from a study by the OECD (Girouard and André 2005). Moreover, recall that we use a measure of taxes net of transfers. We therefore also need an estimate of the elasticity of transfers to changes in output. Finally, we weigh the elasticities together according to their average share of total net revenues during our sample period.

The tax elasticities estimated by Girouard and André (2005) for Denmark are the following: Income taxes; 1.0. Indirect taxes; 1.0. Corporate taxes; 1.6. Social contributions; 0.7 . We refer the reader to that study for further details.

As for transfers, we follow Girouard and André and assume that unemployment benefits is the only type of transfers that contains a significant cyclical component. We therefore compute the sample average share of unemployment-related transfers to total transfers, and multiply this share by the elasticity of unemployment with respect to the output gap, which Girouard and André estimate to - 7.9 for Denmark.

As noted in the main text, we arrive at an output elasticity of net tax revenues of 2.09 .

\section{Appendix C: Computing Variance Decompositions}

To perform the variance decompositions, we rely on results from spectral analysis. Recall that any covariance-stationary time series can be represented equally well in the frequency domain as in the time domain (Hamilton 1994). In the frequency domain, the spectral density of the process is a measure of the share of the overall variance of the process accounted for at various frequencies. If the spectral density is high at low frequencies, much of the variation of the process can be interpreted as long-term movements in the data, perhaps reflecting an underlying trend.

For our VAR-model outlined in Section 2, the spectral density of $X_{t}$ at any frequency $\omega$ is given by: ${ }^{16}$

$$
S_{X}(\omega)=\left[I-A\left(e^{-i \omega}\right)\right]^{-1} C C^{\prime}\left[I-A\left(e^{-i \omega}\right)^{\prime}\right]^{-1}
$$

Here, $A$ is the coefficient matrix from the VAR regression, and $I$ is the identity matrix. $C$ is the matrix linking the reduced-form residuals of the VAR-regression to the structural shocks of the model, with the property $C C^{\prime}=V$, as described in Subsection 2.2. $i$ denotes complex $i$, so that $i^{2}=-1$. Thus, the function assigns to any frequency $\omega$ a square matrix of complex numbers. However, as pointed out in Hamilton (1994), the complex part of the diagonal elements in this matrix will in fact

\footnotetext{
${ }^{16}$ See Hamilton (1994) or Altig et al. (2005).
} 
be zero. The spectral density at frequency $\omega$ for each of the variables in $Y_{t}$ is given exactly by these (real and non-negative) diagonal elements of the matrix.

We want to compute the variance of each of the variables in $X_{t}$ that is accounted for by each of the shocks in $\varepsilon_{t}$. Recall that in the expression for the spectral density, $C C^{\prime}=V$ denotes the variance-covariance matrix when all the shocks are 'turned on'. Following Altig et al. (2005), in order to compute the spectral density of $X_{t}$ when only the $j$ 'th shock $(j=1, \ldots, 4)$ is turned on, we can replace $C C^{\prime}$ by $C I_{j} C^{\prime}$, where $I_{j}$ is a square matrix of zeros, except for a unit entry in the $j$ 'th diagonal element. In other words,

$$
S_{X}^{j}(\omega)=\left[I-A\left(e^{-i \omega}\right)\right]^{-1} C I_{j} C^{\prime}\left[I-A\left(e^{-i \omega}\right)^{\prime}\right]^{-1}
$$

denotes the spectral density of $X_{t}$ when only shock $j$ is active.

As the spectral density for variable $k$ is given by the $k$ 'th diagonal element of $S_{X}(\omega)$, we can then compute the fraction of the variance of the $k$ 'th variable accounted for by the $j$ 'th shock at frequency $\omega$ as:

$$
\operatorname{var}_{k, j}(\omega)=\frac{\left[S_{X}^{j}(\omega)\right]_{k k}}{\left[S_{X}(\omega)\right]_{k k}}
$$

-where $[M]_{k k}$ denotes element $(k, k)$ of matrix $M$. Observe that by construction:

$$
\sum_{j=1}^{4} \operatorname{var}_{k, j}(\omega)=1
$$

Having decomposed the variance of any variable at any frequency, we can then sum the variance ratios over various frequency bands, for example the business cycle frequencies, and see how important each shock is for each variable within these frequency bands.

\section{References}

Alesina A, Ardagna S (2010) Large changes in fiscal policy: taxes versus spending. Tax Policy Macroeconomy 24(1):35-68

Altig D, Christiano L, Eichenbaum M, Lindé J (2005) Technical appendix to firm-specific capital, nominal rigidities and the business cycle. Technical appendices 09-191. Rev Econ Dyn

Andersen TM (1994) Disinflationary stabilization policy - Denmark in the 1980's. In: Åkerholm J, Giovannini A (eds) Exchange rate policies in the nordic countries. CEPR, London

Auerbach A, Gorodnichenko Y (2012) Measuring the output responses to fiscal policy. Am Econ J Econ Pol 4(2):1-27

Beetsma R, Giuliodori M (2011) The effects of government purchases shocks review and estimates for the EU. Econ J 121(550):4-32

Bergman M, Hutchison M (2010) Expansionary fiscal contractions: re-evaluating the danish case. Int Econ J 24(1):71-93

Bilbiie F, Meier A, Müller G (2008) What accounts for the changes in US fiscal policy transmission? J Money Credit Bank 40(7):1439-1469

Blanchard O, Leigh D (2013) Growth forecast errors and fiscal multipliers. IMF Work Pap 13/1 
Blanchard O, Perotti R (2002) An empirical characterization of the dynamic effects of changes in government spending and taxes on output. Q J Econ 117(4):1329-1368

Caldara D, Kamps C (2012) The analytics of SVARs: a unified framework to measure fiscal multipliers. Finance and economics discussion series 2012-20, board of governors of the federal reserve system

Coenen Günter, Erceg C, Freedman C, Furceri D, Kumhof M, Lalonde R, Laxton D, Lindé J, Mourougane A, Muir D, Mursula S, de Resende C, Roberts J, Roeger W, Snudden S, Trabandt M, in't Veld J (2012) Effects of fiscal stimulus in structural models. Am Econ J Macroecon 4(1):1-49

Corsetti G, Meier A, Müller G (2012) What determines government spending multipliers? Econ Policy 27(72):521-565

Dam NA (2008) Business cycles in Denmark and Europe. Dan J Econ 146(2):135-155

Dam NA, Linaa JG (2005) What drives business cycles in a small open economy with a fixed exchange rate? EPRU working paper series, 05-02, Economic policy research unit, University of Copenhagen

Dickey D, Fuller W (1979) Distribution of the estimators for autoregressive time series with a unit root. J Am Stat Assoc 74:427-431

Duygan-Bump B, Grant C (2009) Household debt repayment behaviour: what role do institutions play? Econ Policy 24:107-140

Favero C, Giavazzi F, Perego J (2011) Country heterogeneity and the international evidence on the effects of fiscal policy. IMF Econ Rev 59(4):652-682

Gali J, Vallés J, Lopez-Salido D (2007) Understanding the effects of government spending on consumption. J Eur Econ 5(1):227-270

Giavazzi F, Pagano M (1990) Can severe fiscal contractions be expansionary? Tales of two small european countries. In: Blanchard O, Fischer S (eds) NBER macroeconomics annual. MIT Press, Cambridge

Giorno C, Richardson P, Roseveare D, van den Noord P (1995) Estimating potential output, output gaps and structural budget balances. OECD economics department working papers, no. 152, OECD

Girouard N, André C (2005) Measuring cyclically-adjusted budet balances for OECD countries. OECD economics department working papers, no. 434, OECD

Hall P (1992) The bootstrap and edgeworth expansion. Springer, New York

Hamilton J (1994) Time series analysis. Princeton, Princeton University Press

Hebous S (2011) The effects of discretionary fiscal policy on macroeconomic aggregates: a reappraisal. J Econ Surv 25(4):674-707

Ilzetzki E, Mendoza E, Vegh C (2013) How big (small?) are fiscal multipliers? J Monet Econ 60(2):239_ 254

Jappelli T (2010) Economic literacy: an international comparison. Econ J 120(548):429-451

Kwiatkowski D, Phillips P, Schmidt P, Shin Y (1992) Testing the null hypothesis of stationarity against the alternative of a unit root. How sure are we that economic time series have a unit root? J Econ 54:159-178

Lane P (2003) The cyclical behaviour of fiscal policy: evidence from the OECD. J Public Econ 87:26612675

Lindé J (2003) Monetary policy shocks and business cycle fluctuations in a small open economy: Sweden 1986-2002. Sveriges Riksbank working paper series, no. 153

Mertens K, Ravn M (2013) A reconciliation of SVAR and narrative estimates of tax multipliers. J Monet Econ, forthcoming

Monacelli T, Perotti R (2008) Openness and the sectoral effects of fiscal policy. J Eur Econ Assoc 6(23):395-403

Monacelli T, Perotti R (2010) Fiscal policy, the real exchange rate, and traded goods. Econ J 120(544):437-461

Nakamura E, Steinsson J (2013) Fiscal stimulus in a monetary union: evidence from US regions. Am Econ Rev, forthcoming

Pedersen EH, Plagborg-Møller M (2010) New calculation of Danmarks Nationalbank's effective kronerate index. Dan Nationalbank Monet Rev 2:139-144

Perotti R (2005) Estimating the effects of fiscal policy. In: Proceedings OECD countries, federal reserve bank of San Francisco

Ramey V (2011) Can government purchases stimulate the economy? J Econ Lit 49(3):673-685

Ramey V, Shapiro M (1998) Costly capital reallocation and the effects of government spending. CarnegieRochester Conf Ser on Public Policy 48(1):145-194 
Ravn M, Schmitt-Grohé S, Uribe M (2012) Consumption, government spending, and the real exchange rate. J Monet Econ 59(3):215-34

Ravn SH (2012) Rules versus dictation: a Taylor rule for Denmark. Dan J Econ 150(1):22-42

Romer C, Romer D (2010) The macroeconomic effects of tax changes: estimates based on a new measure of fiscal shocks. Am Econ Rev 100(3):763-801

Zhang Z, Zhang W (2011) The road to recovery fiscal stimulus financial sector rehabilitation, and potential risks ahead. J Asian Econ 22(4):311-321 